\title{
CERTAIN LIMITATIONS OF THE BACILLUS COLI METHOD IN WATER EXAMINATIONS.
}

\author{
By V. GOVINDA RAJU, B.A., \\ Bacteriologist, Bengal Public Health Laboratory, Assistant Professor, \\ School of Tropical Medicine, Calcutta.
}

THE subject of bacterial standards in water examinations is one about which the experience of different workers in India appears to be distinctly at variance. The first elaborate work on the subject seems to have been carried out by Col. Clemesha at the King Institute of Preventive Medicine, Madras. As a result of these researches he put forward a defence of the $B$. coli method, especially when combined with the separate species method. Dr Hirst, working in Ceylon, obtained results that agreed in many respects with Clemesha's conclusions. The next important work in India is that of Major Morison, in Poona. He found the method to be of value not only in detecting faecal pollution but also took a great step in advance by demonstrating that the amount of faecal pollution, as estimated by this method, bears some ratio to the pathogenicity of the water. While the experience of the above workers has on the whole been favourable to the method, that of some others has been distinctly unfavourable. Col. Liston, working in the Bombay Bacteriological Laboratory, found that the numerical presence of $B$. coli in Bombay water is not proportional to the amount of faecal pollution and that often the organisms thus found in water could not be referred to recent or objectionable faecal pollution. Major MacCombie Young, working in Assam, had a similar experience. He found these organisms to be normal inhabitants of a water which on topographical considerations he believes to be totally free from pollution. He reports that:

"The conclusions at which we arrive from weighing these facts are that the presence in water of Bacillus Grïnthal, B. No. 73, B. coscoroba, B. cloacae and B. No. 109, and with a less degree of certainty $B$. No. 36 , has no reference to pollution or even to a remote pollution as in this case they appear to be normal constituents of an unpolluted water.

These organisms cannot be derived from the faeces of birds as there is no means of access for birds in the enclosure of the Spring. Whether they came from the gut of the earthdwelling insects such as grubs or earthworms is hardly worth discussing. We therefore suggest that these organisms may be allowed to leave our court acquitted of the charge of being at any time implicated in the pollution of water. With all due deference to Major Clemesha's opinion in this connection we would suggest that this series of analyses raises the question whether these organisms are not present in faeces because they are at first present in the water and not vice-versa."

The above brief summary illustrates the diametrically opposite views on the subject held by different workers in India. My recent researches on the 
subject appear to throw some light on some of the possible causes of this divergence of opinion. In view of the fact that a small number of faecal bacilli are not infrequently detected even in waters of known purity I have attempted to find out if the presence of frogs in a water is likely to influence its bacterial flora. A lead-lined wooden box was filled with filtered water and a number of frogs, previously washed with filtered water to free them as far as possible from the organisms adhering to their bodies, were put into the tank. The water of the tank was then examined daily and the results proved positive in that a considerable increase in faecal bacilli took place in the water of the frog tank. Although frogs may be negligible factors in the case of large bodies of water like rivers and tanks which are always subject to an appreciable amount of faecal pollution, they are, however, brought into great prominence in pure upland surface waters. From this it follows that in interpreting the results of bacteriological examinations of upland surface water it is necessary to keep in mind that a small number of faecal bacilli may be derived from the gut of frogs.

Secondly, I have tried to investigate if any increase of faecal bacilli occurs in filtered water $(a)$ when stored, or $(b)$ passing through pipes.

(a) Stored water. At one of the water-works in Bengal the filtered water is stored in a large rectangular underground masonry reservoir. The brick work of the reservoir is exceptionally strong and leakage of subsoil water is excluded, as revealed by a careful inspection of the reservoir when empty. The pumps drawing water therefrom are two in number and are situated at either end of the tank. When both the pumps are working it has been found that the bacterial quality of the water is satisfactory at both ends of the reservoir, when, however, only one pump is working it has been found that invariably a good result is obtained when the sample is collected from the end where the pump is drawing water and an increase in faecal bacilli is noticed if the sample is collected from the other end where the pump is not in action and in consequence the water has undergone some amount of stagnation. These results show that storage of filtered water in underground reservoirs does result in an increase of faecal bacilli if the water is allowed to remain stagnant for some hours. From this it follows that if increase of faecal bacilli is noticed in a reservoir water it should not necessarily be referred to faecal contamination but may simply be the result of stagnation.

(b) Pipe water. I have next tried to find out the effect of stasis on the bacterial content of pipe water. A number of laboratory hydrants were selected and the water was allowed to flow from them for some minutes before collecting a sample. The hydrant was then closed and the water allowed to remain in the pipe for $24-48$ hours when samples were taken for comparison with those previously collected. In this way 68 experiments were made. In only 8 per cent. of the experiments an increase occurred in the faecal bacilli count whereas in 66 per cent. of the experiments the faecal bacilli count remained apparently unaltered, and there was a reduction in 26 per cent. of 
the experiments. These results demonstrate that stasis in pipes does not lead to an increase of faecal bacilli, although the total bacterial count is affected thereby and that any alteration in numbers taking place in the faecal bacilli as a result of stasis in the pipes is in the direction of reduction.

The next point investigated was the possible effect of passage through pipes upon the bacterial content of water. The source of the supply was the same municipal hydrant water above referred to. This always shows a fair degree of purity and faecal bacilli are invariably absent from 10 c.c. of water. When, however, this water is stored in iron tanks and passed through pipes, the water drawn from the taps shows very different results. Thus, of 77 samples examined at different times of the year, 44 showed faecal bacilli in 1 c.c. of water and 25 in 10 c.c. The faecal bacilli isolated were typical of recent faecal contamination. Judging only from the fact that 90 per cent. of those samples examined showed a large number of faecal bacilli, few would hesitate to condemn such water as showing distinct signs of faecal pollution. There is, however, no question whatever of any faecal contamination having taken place. The municipal hydrant is only 20 yards away from the laboratory iron tank into which the water discharges and the latter is placed above ground on supports. From this tank the water is pumped on to overhead tanks which are roofed in so that at no stage can any objectionable matter get into the water excepting perhaps a few mosquito larvae. Therefore it is obvious that the large increase of faecal bacilli in the tap water is not to be attributed to faecal contamination but to multiplication in the tanks and to passage through dirty pipes. There appears to be a considerable accumulation of faecal bacilli in the coating of the pipes and these are washed into the water as it flows through them. The importance of this finding lies in the fact that were it not for careful study of the circumstances these hydrant waters would have been condemned as showing undoubted signs of faecal pollution. The deduction to be drawn from this series of experiments is that the results of bacteriological examination of water in certain circumstances may be misleading as the faecal bacilli do, under favourable conditions, multiply to a considerable extent and give rise to an entirely erroneous impression of the quality of water as regards faecal pollution. In the light of these facts the results obtained by Col. Liston in Bombay and Major MacCombie Young in Assam are not at all surprising, as they have been dealing with water which had flowed through miles of piping. It is therefore highly probable that the long sojourn in both the above cases in pipes has brought about an increase in faecal bacilli similar to what I have just described.

\section{Summary and Conclusion.}

Contradictory opinions are at present held on the subject of bacterial standards of purity of water in India. My recent researches tend to throw some light on some of the causes of this divergence of opinion. The presence of frogs in water has been found to be responsible for an increase in faecal 
bacilli which, though negligible in the case of large bodies of water, is apt to be misleading in the case of waters of great purity. Stasis in reservoirs and passage through pipes may be responsible for a considerable increase in faecal bacilli in water, so that a mere increase in the number of faecal bacilli in a reservoir or pipe water does not necessarily indicate faecal contamination but may simply be due to stasis in reservoirs or flow through pipes. These findings lead to two conclusions of importance in regard to the bacteriological examination of water: (1) in testing for the bacterial efficiency of sand filters, samples should be collected from the filter well and not from the clear water reservoir where water is usually stagnant for some hours; $(2)$ in interpreting the results of the examination of pipe waters the possibility of an increase of $B$. coli having occurred through multiplication in the pipes should always be borne in mind before inferring that such increase is indicative of faecal contamination or leakage in the mains. 